University of Montana

ScholarWorks at University of Montana

\title{
A Global Gridded Dataset of GRACE Drought Severity Index for 2002-14: Comparison with PDSI and SPEI and a Case Study of the Australia Millennium Drought
}

Meng Zhao

A. Geruo

I. Velicogna

John S. Kimball

University of Montana - Missoula

Follow this and additional works at: https://scholarworks.umt.edu/ntsg_pubs Let us know how access to this document benefits you.

\section{Recommended Citation}

Zhao, M., G. A, I. Velicogna, and J.S. Kimball, 2017: A Global Gridded Dataset of GRACE Drought Severity Index for 2002-14: Comparison with PDSI and SPEI and a Case Study of the Australia Millennium Drought. J. Hydrometeor., 18, 2117-2129, https://doi.org/10.1175/JHM-D-16-0182.1

This Article is brought to you for free and open access by the Numerical Terradynamic Simulation Group at ScholarWorks at University of Montana. It has been accepted for inclusion in Numerical Terradynamic Simulation Group Publications by an authorized administrator of ScholarWorks at University of Montana. For more information, please contact scholarworks@mso.umt.edu. 


\title{
${ }^{2}$ A Global Gridded Dataset of GRACE Drought Severity Index for 2002-14: Comparison with PDSI and SPEI and a Case Study of the Australia Millennium Drought $\mathscr{}$
}

\author{
Meng Zhao And Geruo A \\ Department of Earth System Science, University of California, Irvine, Irvine, California
}

ISABELLA VELICOGNA

Department of Earth System Science, University of California, Irvine, Irvine, and Jet Propulsion Laboratory, California Institute of Technology, Pasadena, California

JOHN S. KIMBALL

Numerical Terradynamic Simulation Group, College of Forestry and Conservation, University of Montana, Missoula, Montana

(Manuscript received 1 August 2016, in final form 24 April 2017)

\begin{abstract}
A new monthly global drought severity index (DSI) dataset developed from satellite-observed time-variable terrestrial water storage changes from the Gravity Recovery and Climate Experiment (GRACE) is presented. The GRACE-DSI record spans from 2002 to 2014 and will be extended with the ongoing GRACE and scheduled GRACE Follow-On missions. The GRACE-DSI captures major global drought events during the past decade and shows overall favorable spatiotemporal agreement with other commonly used drought metrics, including the Palmer drought severity index (PDSI) and the standardized precipitation evapotranspiration index (SPEI). The assets of the GRACE-DSI are 1) that it is based solely on satellite gravimetric observations and thus provides globally consistent drought monitoring, particularly where sparse ground observations (especially precipitation) constrain the use of traditional model-based monitoring methods; 2$)$ that it has a large footprint $(\sim 350 \mathrm{~km})$, so it is suitable for assessing regional- and global-scale drought; and 3) that it is sensitive to the overall terrestrial water storage component of the hydrologic cycle and therefore complements existing drought monitoring datasets by providing information about groundwater storage changes, which affect soil moisture recharge and drought recovery. In Australia, it is demonstrated that combining GRACE-DSI with other satellite environmental datasets improves the characterization of the 2000s "Millennium Drought" at shallow surface and subsurface soil layers. Contrasting vegetation greenness response to surface and underground water supply changes between western and eastern Australia is found, which might indicate that these regions have different relative plant rooting depths.
\end{abstract}

\section{Introduction}

Drought indices are convenient tools for evaluating drought and its social and ecological impacts, as well as for decision-making in drought prevention and mitigation.

¿ Denotes content that is immediately available upon publication as open access.

Supplemental information related to this paper is available at the Journals Online website: http://dx.doi.org/10.1175/JHM-D-16-0182.s1.

Corresponding author: Meng Zhao, mzhao4@uci.edu
Many global gridded drought indices such as the Palmer drought severity index (PDSI) and the standardized precipitation index (SPI) rely on the accuracy of meteorological inputs and/or simple water balance models. They become unreliable where ground observations (especially precipitation and soil properties) are sparse. Therefore, satellite remote sensing of drought-related variables such as normalized difference vegetation index (NDVI), surface soil moisture (SM), and terrestrial water storage (TWS) have been proposed for complementing more traditional meteorological drought indices (Anderson et al. 2011; Mu et al. 2013; Thomas et al. 2014; AghaKouchak et al. 2015).

Drought indices are generally sensitive to a specific part of the hydrological cycle. The PDSI is sensitive to 
atmosphere moisture demand and near-surface soil moisture content and has been frequently used as a measure of meteorological and soil moisture drought (Mishra and Singh 2010). The SPI measures accumulated precipitation deficits over varying time scales. Shorter time scales are sensitive to surface SM variability, medium scales are sensitive to streamflow and reservoir levels, and longer time scales are sensitive to groundwater variations (McKee et al. 1993). However, this sensitivity pattern varies by region and land cover, which might complicate the choice of SPI time scale in characterizing drought onset, duration, and recovery (Zeng et al. 2008; Wang et al. 2015). An index that reflects total water storage changes in the hydrological cycle is desired for fully characterizing drought evolution and ecosystem response to water supply variations (Van Loon 2015).

TWS estimates derived from the Gravity Recovery and Climate Experiment (GRACE) have been widely used to examine regional-scale droughts worldwide (Yirdaw et al. 2008; Leblanc et al. 2009; Chen et al. 2010a; Long et al. 2013). Li et al. (2012) assimilated GRACE TWS into a land surface model to monitor drought in Europe. Thomas et al. (2014) proposed a framework to quantify drought-induced water storage deficits. However, previous studies did not consider the spatial and temporal variability of local hydroclimatology, which is important for drought comparison across space and time (Zhao et al. 2017). Houborg et al. (2012) account for this issue by deriving local cumulative distribution of dry and wet conditions from the GRACE data assimilation system; however, this system may not be readily available outside of North America. Recently, Zhao et al. (2017) developed a new drought severity index (DSI) based solely on GRACE TWS estimates. Compared to previous GRACE TWS-based drought studies, the GRACE-DSI is calculated without model assimilation and considers spatial and temporal variability of local hydroclimatology. Zhao et al. (2017) evaluate the performance of the GRACE-DSI in the continental United States, where robust drought characterization is available attributed to dense surface observation network and reliable PDSI estimates, whereby GRACE-DSI shows significant agreement with the PDSI and overall favorable spatiotemporal correspondence with satellite retrievals of NDVI and SM.

Here we present a global gridded GRACE-DSI record derived from the standard spherical harmonic approach extending from 2002 to 2014 . We compare the GRACE-DSI record with traditional drought indices including the PDSI and the standardized precipitation evapotranspiration index (SPEI; Vicente-Serrano et al. 2010a) over the global domain, excluding Antarctica and Greenland. We also exclude the barren or sparsely vegetated land cover based on the Moderate Resolution Imaging Spectroradiometer (MODIS) land-cover type data product (MCD12Q1; Friedl et al. 2010) because these regions have low hydroclimatic variability and large DSI error (Dai 2011). We conduct a regional case study of the 2000s "Millennium Drought" in Australia (van Dijk et al. 2013) to evaluate potential synergy between the GRACE-DSI and other satellite environmental data records, including SM and NDVI, for monitoring drought-related impacts on terrestrial ecosystems. We quantify the uncertainty of GRACE-DSI in characterizing drought. We evaluate the impact of using a 13-yr reference period on climatology estimates rather than a longer record. We also discuss DSI results derived from the GRACE mascon solutions.

\section{Data and methodology}

We use Release-05 (RL05) Center for Space Research (CSR) GRACE gravity solutions in the form of spherical harmonic coefficients truncated to degree 60 for the period from April 2002 to October 2014. We substitute the GRACE-derived $C_{20}$ (degree 2 order 0 spherical harmonic coefficient) coefficients with monthly estimates from satellite laser ranging (Cheng et al. 2013). We include degree-1 coefficients calculated as in Swenson et al. (2008) and correct the glacial isostatic adjustment signal following A et al. (2013). To reduce correlated errors, we filter each monthly field following Swenson and Wahr (2006). We convolve the filtered coefficients with a $350-\mathrm{km}$ radius Gaussian averaging function (Wahr et al. 1998) and calculate the monthly TWS mass anomalies relative to the 2002-14 mean on a $1^{\circ} \times 1^{\circ}$ latitude-longitude grid.

We use the $2.5^{\circ}$ global self-calibrated PDSI developed by Dai (2011). The PDSI uses a two-layer model to assess soil water balance by accounting for both water supply and demand (Palmer 1965). The PDSI values correlate with top 1-m depth soil moisture observations over the United States, the former Soviet Union, Mongolia, and China, and with streamflow over major global river basins (Dai et al. 2004; Dai 2011).

We use the $0.5^{\circ}$ global SPEI developed by VicenteSerrano et al. (2010a). The SPEI evaluates accumulated precipitation minus potential evapotranspiration (PET) over multiple time scales up to 48 months (VicenteSerrano et al. 2010b). The SPEI extends the SPI by incorporating PET in determining drought and shows advantages over the SPI in capturing temperature impact on water demand (Vicente-Serrano et al. 2014).

In the Australian case study, we use remotely sensed $0.25^{\circ} \mathrm{SM}$ data from the European Space Agency 
Climate Change Initiative (Liu et al. 2011, 2012). The SM record employs satellite passive and active microwave sensor data with improved spatial and temporal coverage and resolution. We also use the MODIS monthly Climate Model Grid $0.05^{\circ}$ NDVI (MOD13C2; Huete et al. 2002) as a proxy for drought-sensitive vegetation growth changes. Previous studies have shown that, at the site scale, changes in NDVI are sensitive to root-zone SM variations in dry regions (e.g., Wang et al. 2007; Schnur et al. 2010). Recent studies confirmed this result at the regional scale in Australia (Chen et al. 2014; Yang et al. 2014; De Keersmaecker et al. 2017).

For each grid cell, the GRACE-DSI is defined as the standardized anomalies of GRACE TWS as follows:

$$
\operatorname{GRACE}-D S I_{i, j}=\frac{\mathrm{TWS}_{i, j}-\overline{\mathrm{TWS}}_{j}}{\sigma_{j}},
$$

where $i$ is year ranging from 2002 to $2014 ; j$ is month ranging from January to December; and $\overline{\mathrm{TWS}}_{j}$ and $\sigma_{j}$ are the mean and standard deviation of TWS anomalies in month $j$, respectively. The GRACE-DSI is a dimensionless quantity that detects both drought and abnormally wet events: less than -2.0 is an exceptional drought, from -1.99 to -1.60 is an extreme drought, from -1.59 to -1.30 is a severe drought, from -1.29 to -0.80 is a moderate drought, from -0.79 to -0.50 is abnormally dry, from -0.49 to 0.49 is near normal, from 0.50 to 0.79 is slightly wet, from 0.80 to 1.29 is moderately wet, from 1.30 to 1.59 is very wet, from 1.60 to 1.99 is extremely wet, and higher than 2.0 is exceptionally wet.

Because of the truncation and filtering applied to reduce short-scale errors in GRACE, each GRACE-DSI grid cell represents conditions averaged over a $350-\mathrm{km}$ radius footprint (Velicogna and Wahr 2006, 2013). For consistency, all datasets are processed the same as the GRACE data, that is, expanded in spherical harmonic, truncated to degree 60 , filtered, spatially smoothed, and projected onto a $1^{\circ} \times 1^{\circ}$ grid (Velicogna et al. 2012). To bring the data comparison to the same reference period, we standardize the PDSI, SPEI, SM, and NDVI relative to the GRACE-DSI period (2002-14), herein referred to as PDSI- $Z$, SPEI- $Z$, SM- $Z$, and NDVI- $Z$ using the following equation:

$$
X-Z_{i, j}=\frac{X_{i, j}-\bar{X}_{j}}{\sigma_{j}},
$$

where $X$ represents PDSI, SPEI, SM, or NDVI and $\bar{X}_{j}$ and $\sigma_{j}$ are the monthly mean and standard deviation of $X$ calculated from the same years and months used for the GRACE-DSI. This standardization process has also been employed in previous drought index studies (Anderson et al. 2011, 2013; Mu et al. 2013).
We calculate the GRACE-DSI uncertainty due to GRACE measurement error and leakage error. At every grid cell, we estimate the GRACE measurement error following Wahr et al. (2006) and the leakage error following Landerer and Swenson (2012). A synthetic TWS field from the Community Land Model, version 4.5 (CLM4.5), is used as a realistic representation of the observed TWS signal. The leakage error is defined at each grid cell as the RMS difference between the original and the GRACE-like processed CLM4.5 TWS time series (i.e., converted into harmonics, truncated to degree 60 , de-striped, spatially smoothed, and converted to $1^{\circ} \times 1^{\circ}$ regular longitude-latitude grids). The total GRACE error is the summation of the measurement and leakage error in quadrature. We then use a Monte Carlo simulation to estimate the DSI error. At each grid cell, we generate an ensemble of 1000 normally distributed zero mean random noise time series ( $\sigma=$ total GRACE error). We compute the GRACE-DSI for each of those 1000 simulations and calculate the sample distances from their monthly sample means. The resulting sample distances follow a normal distribution, and we set the one standard deviation of the sample distances as the error of GRACE-DSI. Our GRACE-DSI uncertainty estimate is conservative as it assumes that all nonannual and nonsemiannual variations in GRACE data are due to measurement errors. This assumption overestimates the GRACE-DSI error in regions where large nonseasonal variability is observed, for instance due to extreme drought and flooding (Wahr et al. 2006; Tiwari et al. 2009). For the Australian case study, we adopt the same approach to provide a conservative error estimate for the NDVI- $Z$ and SM- $Z$ records.

\section{Results}

Figure 1 shows the global distribution of GRACEDSI, PDSI- $Z$, and SPEI- $Z$ at selected time scales for July 2010, a month in which major drought conditions occurred worldwide (AghaKouchak et al. 2015). The three indices show agreement in the intensity and spatial distribution of drought conditions in western Russia, Southeast Asia, and northern India. Differences are observed in regions including northern China and mainland Australia. The GRACE-DSI and 1-month SPEI- $Z$ show severe drought in northern China, whereas the PDSI- $Z$ and longer-time-scale SPEI- $Z$ ( $>6$ months) show only moderate drought or near-normal conditions. In mainland Australia, the GRACE-DSI shows a similar drought pattern as the 36-month SPEI- $Z$, but more severe and widespread drought than the PDSI- $Z$. In the Amazon, the GRACE-DSI and PDSI- $Z$ capture similar drought intensity and extent. The SPEI- $Z$ also 


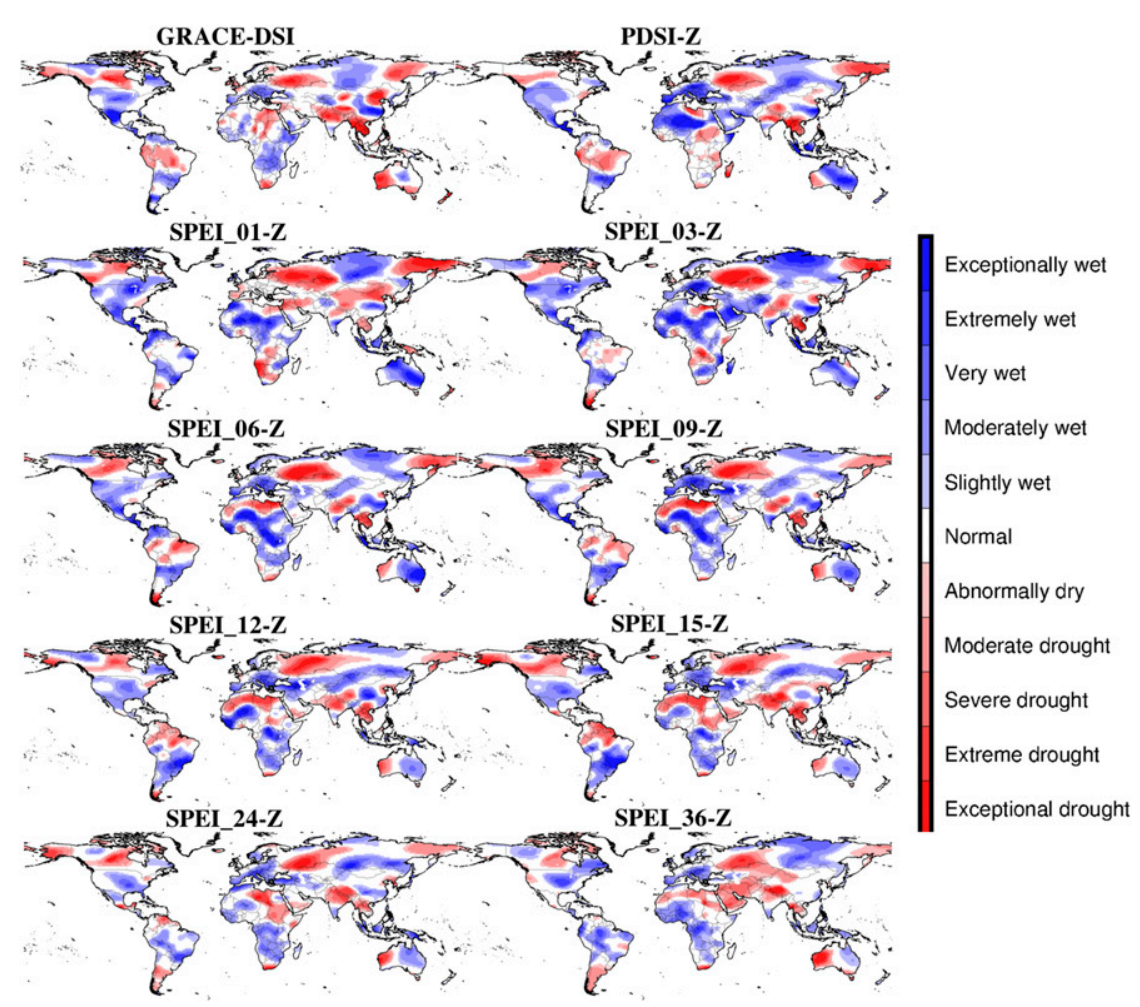

FIG. 1. Global patterns of the GRACE-DSI, PDSI- $Z$, and SPEI- $Z$ drought metrics at selected time scales $(1,3,6,9,12,15,24$, and 36 months) for July 2010.

detects drought in the Amazon, but with varying extent and intensity for different time scales. Wet events are also observed by these indices, but with different extents and magnitudes. For instance, all indices capture the flooding in China except the 36-month SPEI- $Z$. The GRACEDSI, PDSI- $Z$, and shorter-than-15-months SPEI- $Z$ observe the wetting in Pakistan (Webster et al. 2011), whereas the long-time-scale SPEI- $Z$ does not detect this wetting event. The GRACE-DSI characterizes the southern Africa wetting as a very wet to extremely wet event, which is consistent with other observation-based drought indices (AghaKouchak et al. 2015). This event, however, is missed by the PDSI- $Z$ and short-time-scale SPEI- $Z$ ( $<6$ months).

Figure 2 shows time series of the GRACE-DSI, PDSI- $Z$, and SPEI- $Z$ at selected time scales for four locations where major drought events have been reported. The GRACE-DSI shows generally close agreement with the PDSI- $Z$, with a 1 -month delay behind PDSI- $Z$ in response to drought evolution for the 2010 western Russian drought (Fig. 2a; Yoshida et al. 2015) and the 200506 vegetation drought in East Africa (Fig. 2c; Rulinda et al. 2012). In the Amazon, the GRACE-DSI is concurrent with the PDSI- $Z$ and captures the extraordinary 2005 and 2010 droughts in this region as well as the exceptional 2009 flooding (Fig. 2b; Zeng et al. 2008; Chen et al. 2010b; Lewis et al. 2011).

The GRACE-DSI agrees well with the 6-12-month SPEI- $Z$ (Figs. 2i-p). The GRACE-DSI also captures drought events detected by the shorter-time-scale SPEI- $Z$. For instance, the GRACE-DSI captures the short-term 2005/06 winter drought in western Russia (Figs. 2e,i,m). This event is well captured by the 1-12-month SPEI- $Z$ but is missed by the 24-month SPEI- $Z$. The GRACEDSI captures the severe short-term 2010 drought and the 2011/12 winter drought in northern China (Barriopedro et al. 2012), which are both missed by other indices except for the 1-month SPEI- $Z$ (Fig. 2h). In the Amazon, the GRACE-DSI agrees better with the SPEI- $Z$ at time scales shorter than 6 months (Figs. 2f,j).

Figure 3 shows the spatial distribution of monthly GRACE-DSI correlations with the PDSI- $Z$ and SPEI- $Z$ at selected time scales. The correlation between the GRACE-DSI and PDSI- $Z$ is significant at the $95 \%$ confidence level over $91 \%$ of our study domain with an area-weighted mean correlation coefficient of 0.54 (Fig. 3a). The 1-month SPEI- $Z$ has a low correlation with the GRACE-DSI in most regions (Fig. 3b). The correlation increases in magnitude and spatial extent at 


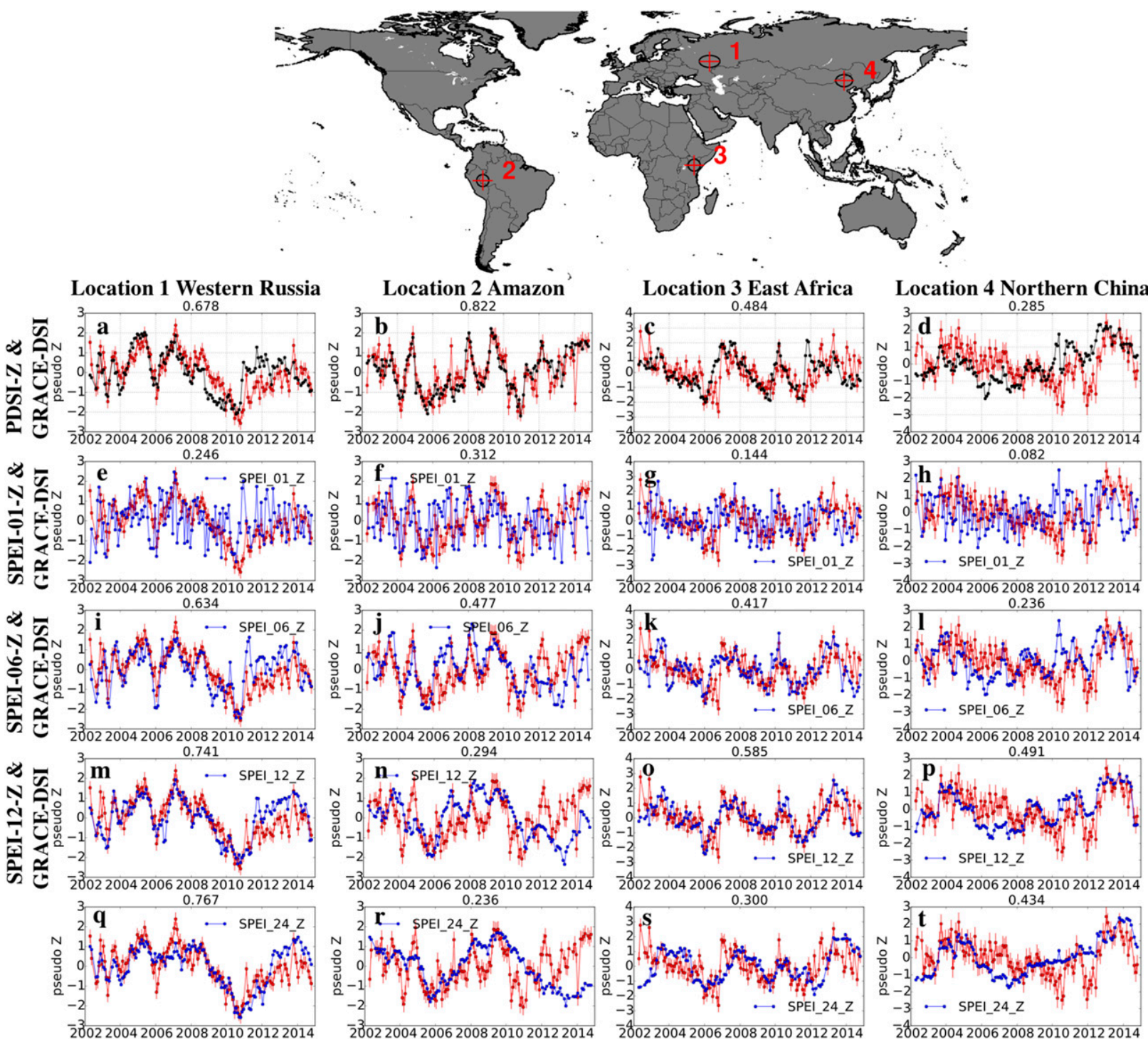

FIG. 2. Time series of the GRACE-DSI (red), PDSI- $Z$ (black), and SPEI- $Z$ (blue) at selected time scales at four locations annotated with $350-\mathrm{km}$ radius footprints in the map. The geographic coordinates are $\left(54^{\circ} \mathrm{N}, 46^{\circ} \mathrm{E}\right),\left(8^{\circ} \mathrm{S}, 72^{\circ} \mathrm{W}\right),\left(0^{\circ}, 38^{\circ} \mathrm{E}\right)$, and $\left(44^{\circ} \mathrm{N}, 116^{\circ} \mathrm{E}\right)$ for locations 1-4, respectively. Note that the GRACE-DSI is the same for all plots in the same location. Error bar on GRACE-DSI represents the GRACE-DSI uncertainty due to GRACE measurement and leakage errors. Pearson correlation coefficient of each comparison is shown on top of each plot. Correlation coefficients larger than 0.17 are significant at the $95 \%$ confidence level.

time scales of 3-18 months and weakens at time scales of 18-48 months (Figs. 3c-i). The GRACE-DSI correlation with SPEI- $Z$ is significant at the $95 \%$ confidence level over $90 \%$ of our study domain at time scales from 5 to 10 months with area-weighted average correlation coefficients above 0.43. Generally, the GRACE-DSI and SPEI- $Z$ have the highest correlation at time scales of 6-18 months (Figs. 3d-f).

Distinct rainfall and drought patterns were documented between western and eastern Australia during the Millennium Drought period (Beard et al. 2011; van Dijk et al. 2013). Figures $4 b$ and $4 c$ show the time series of the GRACE-DSI, SM- $Z$, and NDVI- $Z$ for western Australia (location 1) and eastern Australia (location 2). The GRACE-DSI and NDVI- $Z$ have much smaller uncertainty than SM- $Z$. These satellite-based metrics show overall consistent temporal variations, but differences in trends and magnitude. From 2002 to late 2009, the GRACE-DSI shows statistically significant drying trends in both locations $\left(-0.27 \pm 0.03 \mathrm{yr}^{-1}, p<0.001\right.$ for western Australia and $-0.07 \pm 0.02 \mathrm{yr}^{-1}, p<0.005$ for eastern Australia). A significant NDVI- $Z$ decreasing trend $\left(-0.08 \pm 0.04 \mathrm{yr}^{-1}, p<0.05\right)$ is observed in western Australia but not in eastern Australia. The 


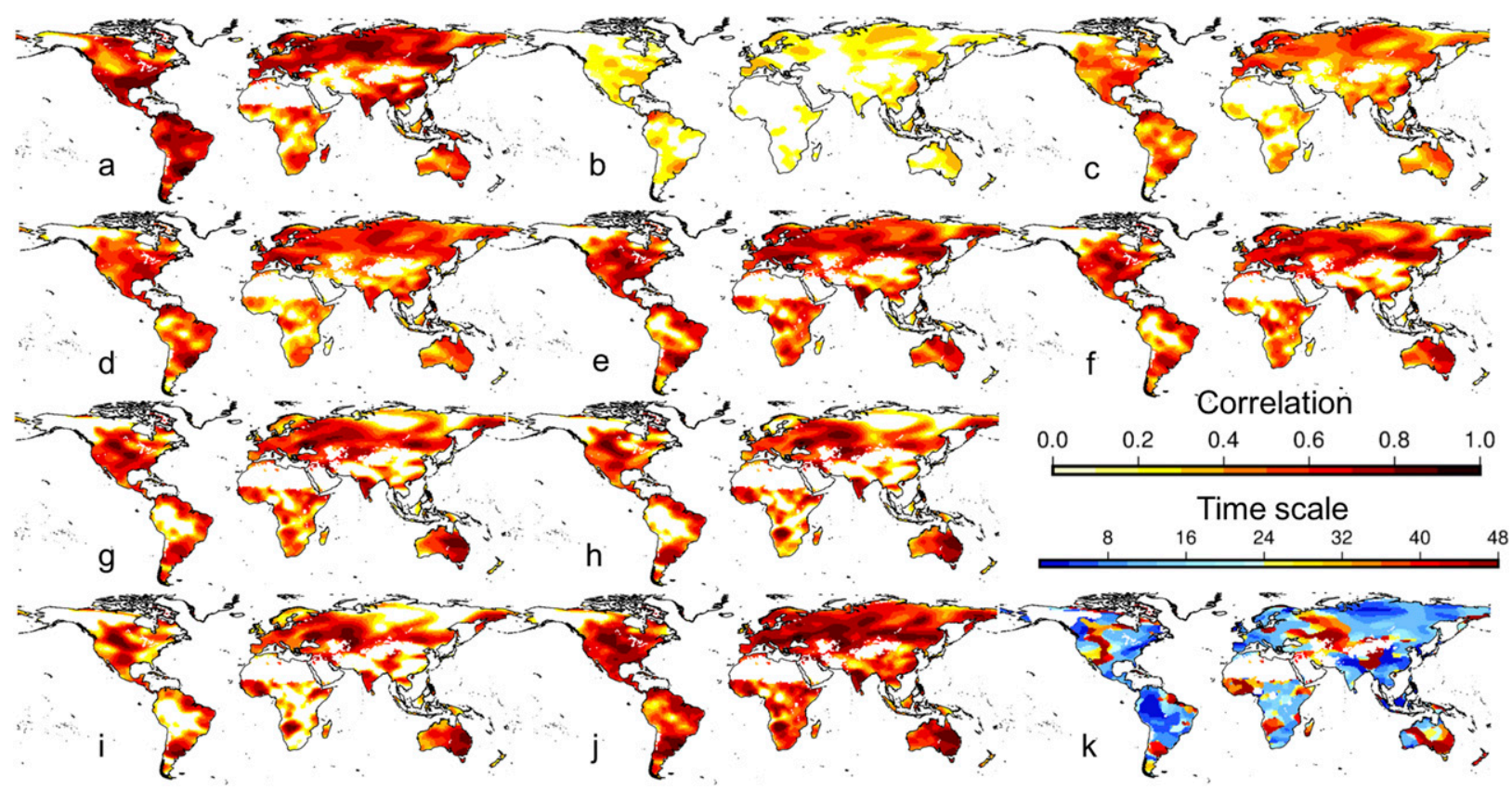

FIG. 3. Correlation between monthly (a) GRACE-DSI and PDSI- $Z$ and (b)-(i) GRACE-DSI and SPEI- $Z$ at time scales of $1,3,6,12,18$, 27, 36, and 48 months, respectively. (j) Max correlation between monthly GRACE-DSI and SPEI- $Z$ at various time scales. (k) Time scale of SPEI- $Z$ in which the max correlation in (j) is recorded. Insignificant correlation coefficients $(p>0.05)$ are masked out in (a)-(j).

SM- $Z$ shows no trend in either location. During the extreme 2010/11 La Niña-induced flooding (Beard et al. 2011), the SM- $Z$ increases earlier than GRACE-DSI at both locations. The NDVI- $Z$ increases concurrently with
GRACE-DSI in western Australia but responds simultaneously with SM- $Z$ in eastern Australia. For the entire study period, the GRACE-DSI has consistently good agreement with NDVI- $Z$ at both locations with a

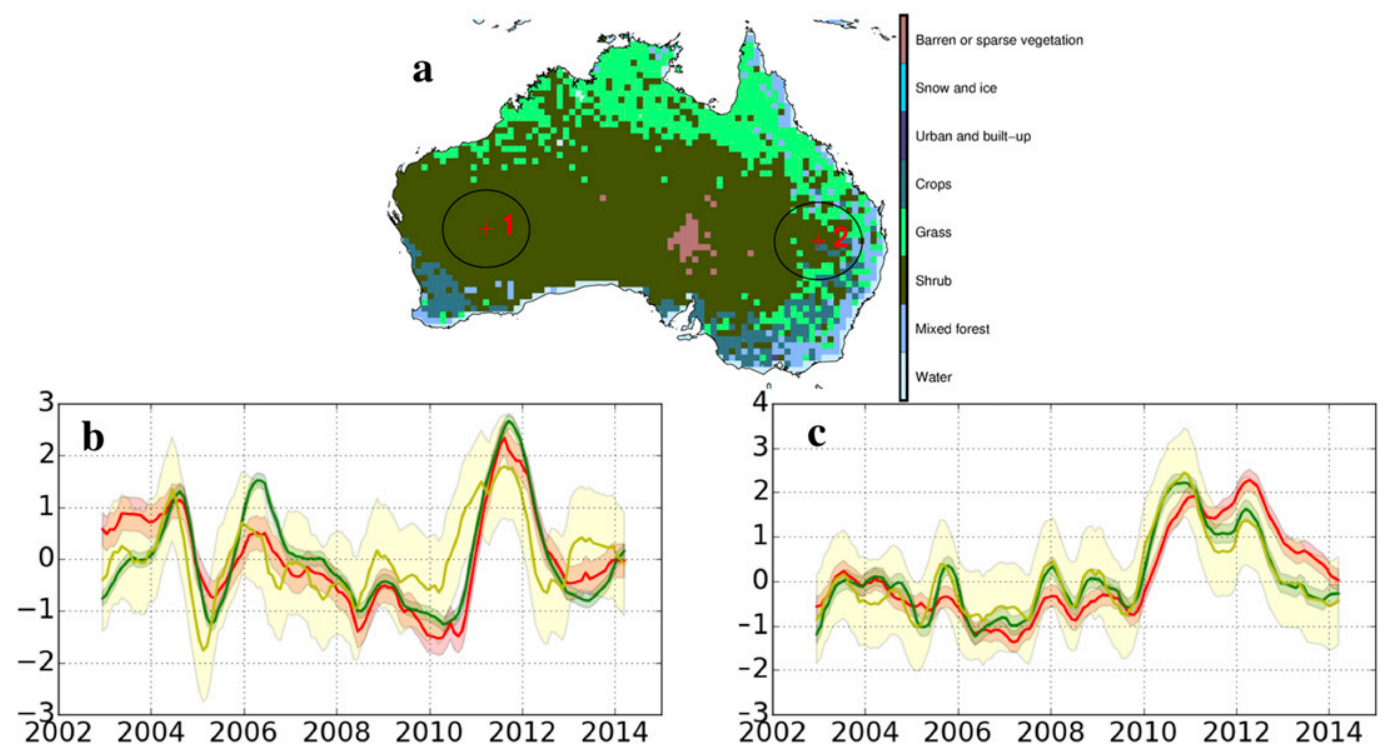

FIG. 4. (a) Time series of GRACE-DSI (red), satellite-retrieved SM- $Z$ (yellow), and NDVI- $Z$ (green) for two locations in mainland Australia annotated with $350-\mathrm{km}$ footprints in the land-cover map. (b) Location $1\left(27^{\circ} \mathrm{S}\right.$, $\left.121^{\circ} \mathrm{E}\right)$ in western Australia and (c) location $2\left(28^{\circ} \mathrm{S}, 148^{\circ} \mathrm{E}\right)$ in eastern Australia. Time series are smoothed using a quadratic polynomial filter with a 13-month window (Savitzky and Golay 1964). Uncertainties of these satellite records are shaded in corresponding colors. The errors of SM- $Z$ and NDVI- $Z$ are estimated conservatively in a similar manner as the GRACE-DSI considering both measurement error and leakage error. 


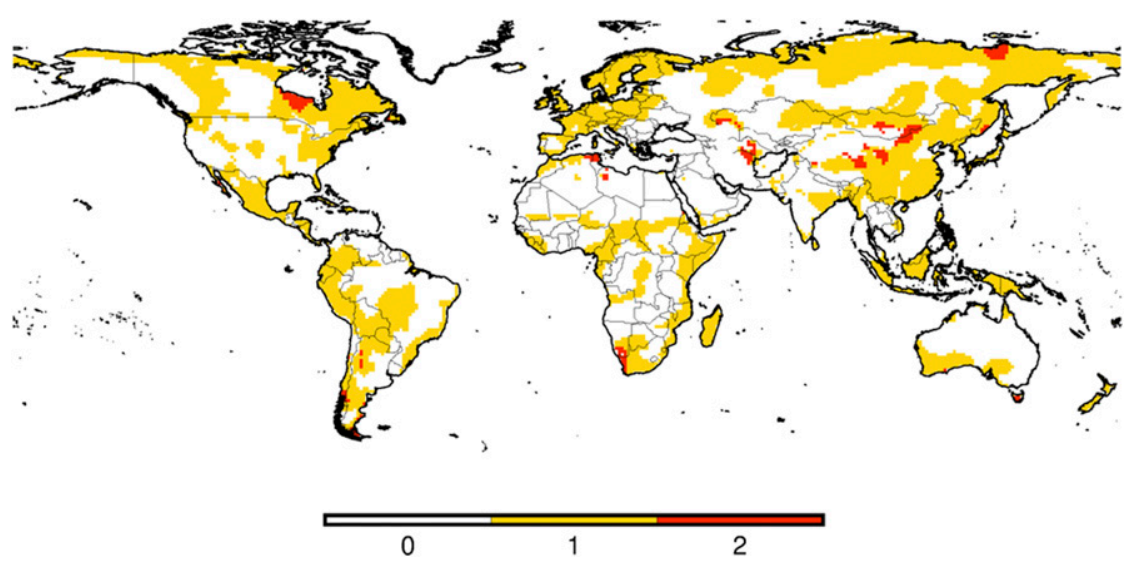

FIG. 5. Global distribution of GRACE-DSI uncertainty in drought category excluding Antarctica, Greenland, and barren grounds.

correlation coefficient $R$ of 0.80 and root-mean-square error (RMSE) of 0.60 . SM- $Z$ has good agreement with NDVI- $Z$ in eastern Australia $(R=0.84, \mathrm{RMSE}=0.57)$ but less agreement with NDVI- $Z$ in western Australia $(R=0.53$, RMSE $=0.96)$.

Figure 5 shows the GRACE-DSI uncertainty in drought category caused by GRACE measurement and leakage errors. We find that GRACE-DSI characterizes drought severity with an uncertainty less than one category (i.e., DSI error $<0.4$, one drought category interval) in $47 \%$ of our study domain (all land regions excluding Antarctica, Greenland, and barren grounds), with one category uncertainty $(0.4 \leq$ DSI error $<0.8)$ in $51 \%$ and with two categories uncertainty (DSI error $\geq 0.8$ ) in $2 \%$.

\section{Discussion}

\section{a. GRACE-DSI comparison with PDSI and SPEI}

The three indices adopt different water balance concepts and address different hydrological processes. The GRACE-DSI is based on direct measurements of water balance that account for water supply from precipitation and water demand from actual evapotranspiration and runoff. The PDSI also accounts for the net water changes but through a simplified two-layer bucket model, which usually represents the water balance of shallow soil depth (Dai 2011). The GRACE-DSI captures total water supply conditions while PDSI- $Z$ captures conditions relative to the shallow-depth water storage. For instance, in July 2010 over eastern Australia (Fig. 1), the GRACE-DSI captures the groundwater deficit near the end of the Millennial Drought (van Dijk et al. 2013; Leblanc et al. 2009, 2012) while the PDSI shows surface water replenishment from the $2010 \mathrm{La}$
Niña event (Beard et al. 2011). The difference in water balance concepts causes the two indices to capture different long-term trends in surface or deeper water storage; this is the case for northern China (Fig. 2d) where the GRACE-DSI indicates a drying trend in overall water storage from 2002 to 2012 while the PDSI- $Z$ suggests a surface wetting trend from 2006 to 2014. This agrees with the observation from Qin et al. (2015) in the same area that surface soil moisture and NDVI are increasing during our study period despite significantly decreasing annual precipitation trend. For this reason, we find a low temporal correlation in this region between GRACE-DSI and PDSI- $Z$ for the entire time series $(R=0.29, p<0.05)$ while the correlation between the detrended time series increases to $0.50(p<0.05)$.

In addition, the response time of shallow soil moisture to drought can be shorter than the overall water storage (e.g., Van Loon 2015). This explains the 1-month lag delay between the GRACE-DSI and PDSI- $Z$ for the 2010 western Russian drought and the 2005-06 East Africa drought (Figs. 2a,c; Rulinda et al. 2012; Yoshida et al. 2015). Groundwater pumping and agricultural irrigation can also delay the response of GRACE-DSI to natural drought evolution, which would affect its agreement with PDSI in heavily irrigated areas (Dai 2011).

The SPEI- $Z$ assesses the climatic water balance (precipitation minus potential evapotranspiration) over multiple time scales (Vicente-Serrano et al. 2010a). The GRACE-DSI represents moisture variations from all hydrological components. The response time of these components to climatic water balance generally lengthens as they go deeper into the ground (e.g., McKee et al. 1993; Vicente-Serrano et al. 2010a). Therefore, the component that dominates changes in the hydrologic cycle will determine at which time scale SPEI- $Z$ agrees with GRACE-DSI. For instance, the GRACE-DSI only has good agreement 

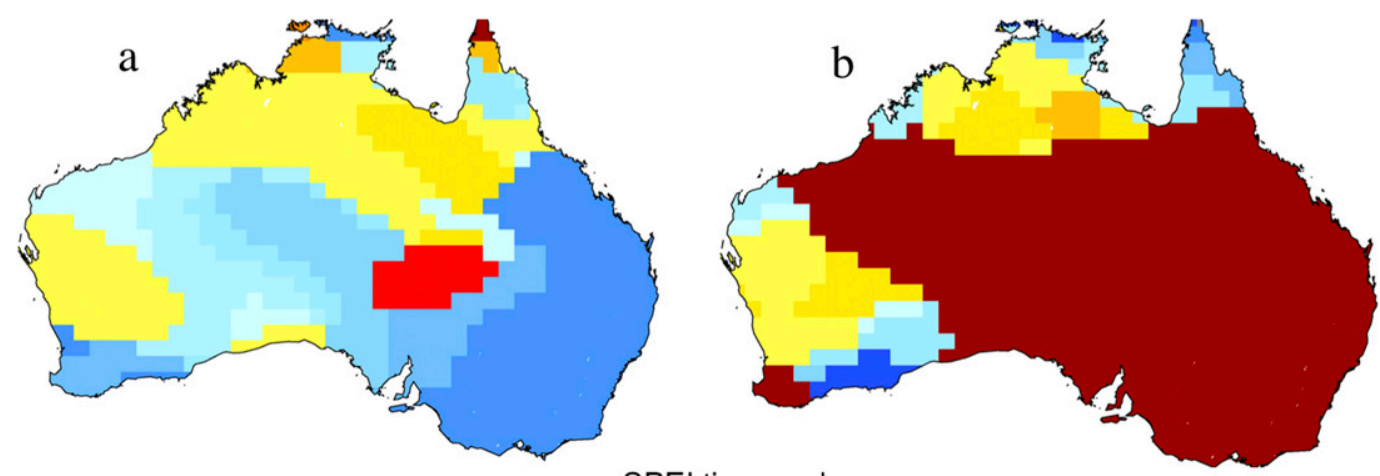

SPEI time scale

$\begin{array}{llllll}3 & 6 & 9 & 12 & 15 & 18\end{array}$

FIG. 6. (a) Time scale by which NDVI- $Z$ achieves max correlation coefficient with SPEI- $Z$. (b) The Australia subregion in Fig. $3 \mathrm{k}$, that is, the time scale by which GRACE-DSI achieves max correlation coefficient with SPEI- $Z$. Note that a large area of (b) saturates at time scales over 20 months. Corresponding max correlation coefficients are significant at the $99 \%$ confidence level for both plots.

with 1-month SPEI- $Z$ in detecting the northern China drought (Fig. 1), indicating that shallow-depth water storage deficit dominates this drought event, in agreement with Barriopedro et al. (2012) describing this event as short-term drought caused by transient summer precipitation shortage. In Australia (Fig. 1), where the GRACEDSI is dominated by severe deep-water depletion near the end of the Millennium Drought (e.g., Leblanc et al. 2012; van Dijk et al. 2013), GRACE-DSI shows a better agreement in terms of spatial pattern with SPEI- $Z$ for time scales longer than 30 months (Fig. 1). In the Amazon we find a maximum correlation for 6-month SPEI- $Z$ (Figs. $2 \mathrm{j}$, $3 \mathrm{k}$ ), indicating that surface and shallow soil moisture dominates the changes in the hydrologic cycle, in agreement with earlier studies in the same area (Han et al. 2009; Kim et al. 2009; Frappart et al. 2012, 2013). These results demonstrate that the time scale at which the SPEI- $Z$ achieves maximum temporal correlation with the GRACE-DSI (optimal time scale) is of potential use to constrain the relative depth of the water component that dominates the overall changes in the water cycle at a specific location. For instance, the optimal time scale in northern and western Australia is much smaller than in southeastern Australia (Fig. 3k). This result suggests that a relatively shallower hydrologic component dominates the overall changes in the water cycle in northern and western Australia compared to southeastern Australia, where severe groundwater depletion dominates the changes in TWS during the Millennium Drought (Leblanc et al. 2009, 2012). We evaluate this hypothesis using NDVI- $Z$ as a proxy for root-zone soil moisture variations (Chen et al. 2014; Yang et al. 2014; De Keersmaecker et al. 2017). We calculate the optimal time scale between SPEI- $Z$ and NDVI- $Z$ in Fig. 6a. In northern and western Australia, we find that the optimal SPEI- $Z$ time scale for NDVI- $Z$ is consistent with the optimal time scale for GRACE-DSI (Fig. 6b), suggesting that root-zone soil moisture variability dominates the overall changes in the water cycle over these regions. This result therefore confirms that changes in the water cycle in northern and western Australia are dominated by a relatively shallower hydrologic component (root-zone soil moisture) than in southeastern Australia (groundwater).

The optimal time scale (Fig. 3k) shows large spatial variability. This variability is consistent among different GRACE processing approaches (see Fig. S3b in the supplemental material). We also find that the spatial pattern of Fig. 3k is insensitive to GRACE measurement errors. Therefore, the result of Fig. 3k is robust. The large spatial variability highlights the geographical complexity of the translation of climatic water balance into hydrologic system (e.g., Tallaksen et al. 2009; Teuling et al. 2013; Van Loon et al. 2012, 2014; Van Loon 2015). This large spatial variability is also observed in previous studies comparing SPEI with PDSI at global scale (Vicente-Serrano et al. 2010b) and comparing SPEI and SPI at local and regional scales with hydrological drought proxies using groundwater and streamflow observations (Bloomfield and Marchant 2013; López-Moreno et al. 2013; Li and Rodell 2015; Kumar et al. 2016). We observe very long time scales (>40 months) over regions such as western Africa; southern Africa; southern South America; and parts of Australia, western Russia, and North America (Fig. 3k). During the analyzed period, those regions have experienced persistent trends in TWS (Long et al. 2017), mainly driven by long-term changes in climatic conditions such as the sustained wetting trend in western and 


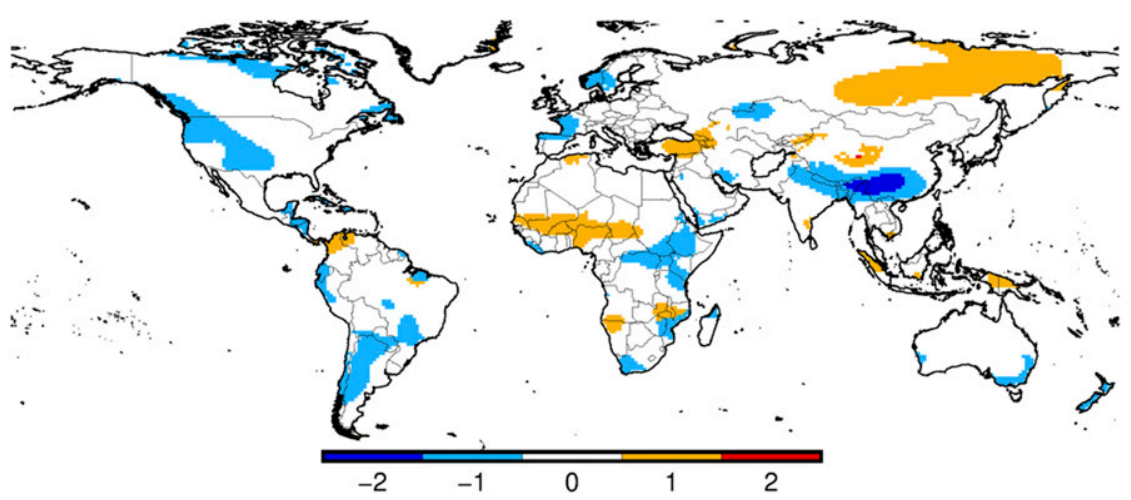

FIG. 7. Drought category overestimation (positive value) and underestimation (negative value) using the 2002-14 reference period rather than the 1982-2014 reference period for the PDSI- $Z$ drought index.

southern Africa (Maidment et al. 2015) and persistent drought conditions in southern South America and Australia (Chen et al. 2010a; van Dijk et al. 2013). In those regions, the GRACE-DSI is largely influenced by long-term accumulation of climatic water balance, therefore achieving maximum correlation with longtime-scale SPEI- $Z$.

\section{b. Australian case study}

From 2002 to late 2009, surface soil moisture (SM-Z) shows no trends but GRACE-DSI indicates significant drying trends in both western and eastern Australia. This suggests gradual depletion of deeper water storage, which is beyond the depth that microwave satellites can sense, such as root-zone moisture and groundwater. Our analyses for location 2 agree with the results from Leblanc et al. $(2009,2012)$ and van Dijk et al. (2013) in the MurrayDarling basin, where soil moisture droughts stabilize at low levels since 2002 while groundwater levels gradually decline until late 2009. Leblanc et al. (2012) also observe a small increase in total water storage from 2007 to 2008 and estimate that about two-thirds of this increase is used to replenish the shallow surface soil moisture reservoir. This is highly consistent with our results in eastern Australia (Fig. 4c). The small increase in total water storage in 2008 greatly reduces the magnitude of the drying trend in eastern Australia from 2002 to late 2009.

The NDVI- $Z$ has different degrees of agreement with SM- $Z$ in western and eastern Australia, but has an overall good and consistent agreement with GRACE-DSI in both locations. This suggests that the GRACE-DSI is a more consistent indicator of plant water availability than surface soil moisture across Australia, in agreement with earlier studies (e.g., Chen et al. 2014; Yang et al. 2014; Wu et al. 2015). From 2002 to late 2009, although SM-Z has no trend, NDVI- $Z$ shows a decreasing trend in western Australia that coincides with the drying trend in
GRACE-DSI. This possibly reflects increasing water stress on plants as the drought propagates from the shallow surface to the deep underground. During and after the 2010/11 La Niña-induced extreme wetting, NDVI- $Z$ closely follows GRACE-DSI in western Australia. These together suggest that deep-rooted and groundwater-dependent plants might dominate vegetation greenness in western Australia. In contrast, NDVI- $Z$ does not show significant decreasing trend from 2002 to late 2009 in eastern Australia, suggesting that vegetation might not be influenced by the gradual depletion of deeper water storage. Overall, NDVI- $Z$ agrees better with SM- $Z$ both in magnitude and temporal variation than with GRACE-DSI in eastern Australia, indicating that shallow-rooted plants might dominate vegetation greenness in this region. This contrasting NDVI response pattern is consistent with the regional distribution of drought-sensitive vegetation in eastern Australia and drought-resistant vegetation in western Australia where water-table depth is much deeper than in the east (Khan et al. 2008; Fan et al. 2013; De Keersmaecker et al. 2015; Seddon et al. 2016).

\section{c. Short data record length}

The initial GRACE-DSI period (2002-14) may not be long enough to sample the full range of wetness and dryness required for a climatological index, for which a climatology of at least 30 years is preferred. To evaluate the potential impact of short data record length on drought characterization, we calculate the RMSE between two PDSI- $Z$ records normalized to 2002-14 and 1982-2014, respectively, using Eq. (2). We find that using the 13-yr climatology, PDSI- $Z$ underestimates drought by one category over $15 \%$ of the study domain (all land regions excluding Antarctica, Greenland, and barren ground) and by two categories over $1 \%$ of the study domain (Fig. 7). These regions experienced a significantly drier mean climate during 2002-14 than during 
1982-2014. We also find that using the 13-yr climatology, PDSI- $Z$ overestimates drought by one category over $12 \%$ of the study domain where the $13-\mathrm{yr}$ mean climate is much wetter and/or the hydroclimatic variability is much smaller than the 33-yr climatology. Therefore, when using GRACE-DSI in these regions, we suggest that the stakeholders correct for the category bias to mitigate the short baseline issue. When comparing the GRACE-DSI with other long-term drought metrics, the bias can also be effectively removed by referencing to the 2002-14 period using the normalization method employed in this study.

\section{d. GRACE-DSI calculated from JPL mascon solutions}

We also calculate GRACE-DSI using the Jet Propulsion Laboratory (JPL) RL05 Mascon solutions (Watkins et al. 2015). Each mascon solves for the monthly gravity field averaged over an equal-area $3^{\circ}$ spherical cap mass concentration block. The spatial representation of the GRACE-DSI from the mascon is therefore different from the spherical harmonics-derived GRACE-DSI for which each $1^{\circ}$ grid cell represents conditions averaged over a $350-\mathrm{km}$ radius footprint. We repeat the drought index intercomparison for the mascon-derived GRACEDSI (see supplemental material for details). Overall, the mascon results are in agreement with the spherical harmonics results except in the Amazon rain forest, where for over a few months we observe north-south stripes (e.g., Fig. S1) in regions characterized by larger errors in the mascon (Watkins et al. 2015; Wiese et al. 2016). The stripes are not visible in the spherical harmonics-derived GRACE-DSI and in the other drought indices (Figs. S2-S4).

\section{Conclusions}

We present a new monthly global DSI developed from satellite-observed time-variable terrestrial water storage changes from GRACE. The initial global GRACEDSI record extends from 2002 to 2014 and will be updated on a regular basis when newly processed GRACE solutions become available. Although currently not in real time, the GRACE-DSI has potential to provide near-real-time drought monitoring capability with the launch of the GRACE Follow-On mission in 2017. Moreover, the GRACE-DSI has several unique advantages that make it valuable to study droughtrelated processes and socioecological impacts. The GRACE-DSI is unaffected by uncertainties associated with traditional model-based indices (e.g., PDSI, SPI, and SPEI), such as dependency on sparse weather station observations or uncertainty from the use of simple water balance models or reanalysis meteorological data.
Therefore, it provides an independent observation benchmark for evaluating model-based drought monitoring tools while providing drought information even where sparse ground observations may constrain other approaches.

The GRACE-DSI is sensitive to changes in the bulk terrestrial water storage component of the hydrologic cycle extending from a plant's root-zone soil moisture to deeper groundwater. In contrast, PDSI represents the water balance of shallow soil depth, and SPEI- $Z$ assesses the climatic water balance (precipitation minus potential evapotranspiration) over multiple time scales. We interpret the differences between GRACE-DSI and those traditional drought indicators in terms of which hydrological component dominates the drought signal. For instance, the low correlation between GRACE-DSI and PDSI- $Z$ in northern China is due to the difference in trend between TWS and shallow water storage. The time scales of maximum correlation between GRACE-DSI and SPEI- $Z$ indicate which component dominates the hydrologic cycle: maximum correlation occurs with shorttime-period SPEI- $Z$ when the hydrological cycle is dominated by changes at shallow depth; maximum correlation occurs with longer-period SPEI- $Z$ when the hydrological cycle changes at depth. For eastern and southeastern Australia, for instance, maximum correlation between GRACE-DSI and SPEI- $Z$ occurs on a longer time scale because the Millennium Drought is dominated by deep-water depletion. The synergistic use of GRACE-DSI with other existing environmental data and drought monitoring tools therefore has potential for improving the characterization of drought (e.g., propagation and recovery) and associated ecological impacts at regional and global scales. In this paper, we demonstrate that combing the GRACE-DSI with other satellite environmental records improves the characterization of the 2000s Australia Millennium Drought, as well as associated vegetation response to water supply changes at surface and subsurface soil layers. A caveat to the application of GRACE-DSI is that it should be used with caution in glaciated areas where the GRACE-DSI might contain ice mass change signals (Jacob et al. 2012).

Acknowledgments. This work was performed at the University of California, Irvine. Meng Zhao is supported by NASA Earth and Space Science Fellowship (NNX16AO64H), and all remaining authors are supported by NASA Grant NNX16AN05G and the Gordon and Betty Moore Foundation (GBMF3269). The GRACE-DSI and ancillary datasets analyzed in this paper will be freely available on the Velicogna's research group website at the University of California, Irvine. We thank two anonymous reviewers and editor Dr. Christa Peters-Lidard for their careful reviews. 


\section{REFERENCES}

A, G., J. Wahr, and S. Zhong, 2013: Computations of the viscoelastic response of a 3-D compressible Earth to surface loading: An application to glacial isostatic adjustment in Antarctica and Canada. Geophys. J. Int., 192, 557-572, doi:10.1093/gji/ggs030.

AghaKouchak, A., A. Farahmand, F. S. Melton, J. Teixeira, M. C. Anderson, B. D. Wardlow, and C. R. Hain, 2015: Remote sensing of drought: Progress, challenges and opportunities. Rev. Geophys., 53, 452-480, doi:10.1002/2014RG000456.

Anderson, M. C., C. Hain, B. Wardlow, A. Pimstein, J. R. Mecikalski, and W. P. Kustas, 2011: Evaluation of drought indices based on thermal remote sensing of evapotranspiration over the continental United States. J. Climate, 24, 20252044, doi:10.1175/2010JCLI3812.1.

_, - J. Otkin, X. Zhan, K. Mo, M. Svoboda, B. Wardlow, and A. Pimstein, 2013: An intercomparison of drought indicators based on thermal remote sensing and NLDAS-2 simulations with U.S. Drought Monitor classifications. J. Hydrometeor. 14, 1035-1056, doi:10.1175/JHM-D-12-0140.1.

Barriopedro, D., C. M. Gouveia, R. M. Trigo, and L. Wang, 2012: The 2009/10 drought in China: Possible causes and impacts on vegetation. J. Hydrometeor., 13, 1251-1267, doi:10.1175/ JHM-D-11-074.1.

Beard, G., E. Chandler, A. B. Watkins, and D. A. Jones, 2011: How does the 2010-11 La Niña compare with past La Niña events? Bull. Aust. Meteor. Oceanogr. Soc., 24, 17-20.

Bloomfield, J. P., and B. P. Marchant, 2013: Analysis of groundwater drought building on the standardized precipitation index approach. Hydrol. Earth Syst. Sci., 17, 4769-4787, doi:10.5194/ hess-17-4769-2013.

Chen, J. L., C. R. Wilson, B. D. Tapley, L. Longuevergne, Z. L. Yang, and B. R. Scanlon, 2010a: Recent La Plata basin drought conditions observed by satellite gravimetry. J. Geophys. Res., 115, D22108, doi:10.1029/2010JD014689.

$\longrightarrow, \ldots$, and $-2010 \mathrm{~b}$ : The 2009 exceptional Amazon flood and interannual terrestrial water storage change observed by GRACE. Water Resour. Res., 46, W12526, doi:10.1029/2010WR009383.

Chen, T., R. A. M. de Jeu, Y. Y. Liu, G. R. van der Werf, and A. J. Dolman, 2014: Using satellite based soil moisture to quantify the water driven variability in NDVI: A case study over mainland Australia. Remote Sens. Environ., 140, 330-338, doi:10.1016/ j.rse.2013.08.022.

Cheng, M., B. D. Tapley, and J. C. Ries, 2013: Deceleration in the Earth's oblateness. J. Geophys. Res., 118, 740-747, doi:10.1002/ jgrb.50058.

Dai, A., 2011: Characteristics and trends in various forms of the Palmer drought severity index during 1900-2008. J. Geophys. Res., 116, D12115, doi:10.1029/2010JD015541.

_ K. E. Trenberth, and T. Qian, 2004: A global dataset of Palmer drought severity index for 1870-2002: Relationship with soil moisture and effects of surface warming. J. Hydrometeor., 5 , 1117-1130, doi:10.1175/JHM-386.1.

De Keersmaecker, W., S. Lhermitte, L. Tits, O. Honnay, B. Somers, and P. Coppin, 2015: A model quantifying global vegetation resistance and resilience to short-term climate anomalies and their relationship with vegetation cover. Global Ecol. Biogeogr., 24, 539-548, doi:10.1111/geb.12279.

- - , M. J. Hill, L. Tits, P. Coppin, and B. Somers, 2017: Assessment of regional vegetation response to climate anomalies: A case study for Australia using GIMMS NDVI time series between 1982 and 2006. Remote Sens., 9, 34, doi:10.3390/rs9010034
Fan, Y., H. Li, and G. Miguez-Macho, 2013: Global patterns of groundwater table depth. Science, 339, 940-943, doi:10.1126/ science.1229881.

Frappart, F., F. Papa, J. S. da Silva, G. Ramillien, C. Prigent, F. Seyler, and S. Calmant, 2012: Surface freshwater storage and dynamics in the Amazon basin during the 2005 exceptional drought. Environ. Res. Lett., 7, 044010, doi:10.1088/ 1748-9326/7/4/044010.

_ - G. Ramillien, and J. Ronchail, 2013: Changes in terrestrial water storage versus rainfall and discharges in the Amazon basin. Int. J. Climatol., 33, 3029-3046, doi:10.1002/joc.3647.

Friedl, M. A., D. Sulla-Menashe, B. Tan, A. Schneider, N. Ramankutty, A. Sibley, and X. Huang, 2010: MODIS Collection 5 global land cover: Algorithm refinements and characterization of new datasets. Remote Sens. Environ., 114, 168-182, doi:10.1016/j.rse.2009.08.016.

Han, S.-C., H. Kim, I.-Y. Yeo, P. Yeh, T. Oki, K.-W. Seo, D. Alsdorf, and S. B. Luthcke, 2009: Dynamics of surface water storage in the Amazon inferred from measurements of inter-satellite distance change. Geophys. Res. Lett., 36, L09403, doi:10.1029/ 2009GL037910.

Houborg, R., M. Rodell, B. Li, R. Reichle, and B. F. Zaitchik, 2012: Drought indicators based on model-assimilated Gravity Recovery and Climate Experiment (GRACE) terrestrial water storage observations. Water Resour. Res., 48, W07525, doi:10.1029/ 2011WR011291.

Huete, A., K. Dian, T. Miura, E. P. Rodriguez, X. Gao, and L. G. Ferreira, 2002: Overview of the radiometric and biophysical performance of the MODIS vegetation indices. Remote Sens. Environ., 83, 195-213, doi:10.1016/S0034-4257(02)00096-2.

Jacob, T., J. Wahr, W. T. Pfeffer, and S. Swenson, 2012: Recent contributions of glaciers and ice caps to sea level rise. Nature, 482, 514-518, doi:10.1038/nature10847.

Khan, S., H. F. Gabriel, and T. Rana, 2008: Standard precipitation index to track drought and assess impact of rainfall on watertables in irrigation areas. Irrig. Drain. Syst., 22, 159-177, doi:10.1007/s10795-008-9049-3.

Kim, H., P. J.-F. Yeh, T. Oki, and S. Kanae, 2009: Role of rivers in the seasonal variations of terrestrial water storage over global basins. Geophys. Res. Lett., 36, L17402, doi:10.1029/2009GL039006.

Kumar, R., and Coauthors, 2016: Multiscale evaluation of the standardized precipitation index as a groundwater drought indicator. Hydrol. Earth Syst. Sci., 20, 1117-1131, doi:10.5194/ hess-20-1117-2016.

Landerer, F. W., and S. C. Swenson, 2012: Accuracy of scaled GRACE terrestrial water storage estimates. Water Resour. Res., 48, W04531, doi:10.1029/2011WR011453.

Leblanc, M. J., P. Tregoning, G. Ramillien, S. O. Tweed, and A. Fakes, 2009: Basin-scale, integrated observations of the early 21st century multiyear drought in southeast Australia. Water Resour. Res., 45, W04408, doi:10.1029/2008WR007333. S. Tweed, A. Van Dijk, and B. Timbal, 2012: A review of historic and future hydrological changes in the MurrayDarling basin. Global Planet. Change, 80-81, 226-246, doi:10.1016/j.gloplacha.2011.10.012.

Lewis, S. L., P. M. Brando, O. L. Phillips, G. M. F. van der Heijden, and D. Nepstad, 2011: The 2010 Amazon drought. Science, 331, 554, doi:10.1126/science. 1200807 .

Li, B., and M. Rodell, 2015: Evaluation of a model-based groundwater drought indicator in the conterminous U.S. J. Hydrol., 526, 78-88, doi:10.1016/j.jhydrol.2014.09.027.

, - B. F. Zaitchik, R. H. Reichle, R. D. Koster, and T. M. van Dam, 2012: Assimilation of GRACE terrestrial water 
storage into a land surface model: Evaluation and potential value for drought monitoring in western and central Europe. J. Hydrol., 446-447, 103-115, doi:10.1016/j.jhydrol.2012.04.035.

Liu, Y. Y., and Coauthors, 2011: Developing an improved soil moisture dataset by blending passive and active microwave satellite-based retrievals. Hydrol. Earth Syst. Sci., 15, 425-436, doi:10.5194/hess-15-425-2011.

, W. A. Dorigo, R. M. Parinussa, R. A. M. de Jeu, W. Wagner, M. F. McCabe, J. P. Evans, and A. I. J. M. van Dijk, 2012: Trend-preserving blending of passive and active microwave soil moisture retrievals. Remote Sens. Environ., 123, 280-297, doi:10.1016/j.rse.2012.03.014.

Long, D., B. R. Scanlon, L. Longuevergne, A. Y. Sun, D. N. Fernando, and H. Save, 2013: GRACE satellite monitoring of large depletion in water storage in response to the 2011 drought in Texas. Geophys. Res. Lett., 40, 3395-3401, doi:10.1002/grl.50655.

—, Y. Pan, J. Zhou, Y. Chen, X. Hou, Y. Hong, B. R. Scanlon, and L. Longuevergne, 2017: Global analysis of spatiotemporal variability in merged total water storage changes using multiple GRACE products and global hydrological models. Remote Sens. Environ., 192, 198-216, doi:10.1016/j.rse.2017.02.011.

López-Moreno, J. I., S. M. Vicente-Serrano, J. Zabalza, S. Beguería, J. Lorenzo-Lacruz, C. Azorin-Molina, and E. Moran-Tejeda, 2013: Hydrological response to climate variability at different time scales: A study in the Ebro basin. J. Hydrol., 477, 175-188, doi:10.1016/j.jhydrol.2012.11.028.

Maidment, R. I., R. P. Allan, and E. Black, 2015: Recent observed and simulated changes in precipitation over Africa. Geophys. Res. Lett., 42, 8155-8164, doi:10.1002/2015GL065765.

McKee, T. B., N. J. Doesken, and J. Kleist, 1993: The relationship of drought frequency and duration to time scales. Preprints, Eighth Conf. on Applied Climatology, Anaheim, CA, Amer. Meteor. Soc., 179-184.

Mishra, A. K., and V. P. Singh, 2010: A review of drought concepts. J. Hydrol., 391, 202-216, doi:10.1016/j.jhydrol.2010.07.012.

Mu, Q., M. Zhao, J. S. Kimball, N. G. McDowell, and S. W. Running, 2013: A remotely sensed global terrestrial drought severity index. Bull. Amer. Meteor. Soc., 94, 83-98, doi:10.1175/ BAMS-D-11-00213.1.

Palmer, W. C., 1965: Meteorological drought. U.S. Weather Bureau Research Paper 45, 58 pp. [Available online at http://www.ncdc. noaa.gov/temp-and-precip/drought/docs/palmer.pdf.]

Qin, Y., D. Yang, H. Lei, K. Xu, and X. Xu, 2015: Comparative analysis of drought based on precipitation and soil moisture indices in Haihe basin of north China during the period of 1960 2010. J. Hydrol., 526, 55-67, doi:10.1016/j.jhydrol.2014.09.068.

Rulinda, C. M., A. Dilo, W. Bijker, and A. Stein, 2012: Characterizing and quantifying vegetative drought in East Africa using fuzzy modeling and NDVI data. J. Arid Environ., 78, 169-178, doi:10.1016/j.jaridenv.2011.11.016.

Savitzky, A., and M. J. E. Golay, 1964: Smoothing and differentiation of data by simplified least squares procedures. Anal. Chem., 36, 1627-1639, doi:10.1021/ac60214a047.

Schnur, M. T., H. Xie, and X. Wang, 2010: Estimating root zone soil moisture at distant sites using MODIS NDVI and EVI in a semi-arid region of southwestern USA. Ecol. Inform., 5, 400409, doi:10.1016/j.ecoinf.2010.05.001.

Seddon, A. W. R., M. Macias-Fauria, P. R. Long, D. Benz, and K. J. Willis, 2016: Sensitivity of global terrestrial ecosystems to climate variability. Nature, 531, 229-232, doi:10.1038/nature16986.

Swenson, S., and J. Wahr, 2006: Post-processing removal of correlated errors in GRACE data. Geophys. Res. Lett., 33, L08402, doi:10.1029/2005GL025285.
—, D. Chambers, and J. Wahr, 2008: Estimating geocenter variations from a combination of GRACE and ocean model output. J. Geophys. Res., 113, B08410, doi:10.1029/2007JB005338.

Tallaksen, L. M., H. Hisdal, and H. A. J. Van Lanen, 2009: Spacetime modelling of catchment scale drought characteristics. J. Hydrol., 375, 363-372, doi:10.1016/j.jhydrol.2009.06.032.

Teuling, A. J., and Coauthors, 2013: Evapotranspiration amplifies European summer drought. Geophys. Res. Lett., 40, 20712075, doi:10.1002/grl.50495.

Thomas, A. C., J. T. Reager, J. S. Famiglietti, and M. Rodell, 2014: A GRACE-based water storage deficit approach for hydrological drought characterization. Geophys. Res. Lett., 41, 1537-1545, doi:10.1002/2014GL059323.

Tiwari, V. M., J. Wahr, and S. Swenson, 2009: Dwindling groundwater resources in northern India, from satellite gravity observations. Geophys. Res. Lett., 36, L18401, doi:10.1029/2009GL039401.

van Dijk, A. I. J. M., H. E. Beck, R. S. Crosbie, R. A. M. de Jeu, Y. Y. Liu, G. M. Podger, B. Timbal, and N. R. Viney, 2013: The Millennium Drought in southeast Australia (2001-2009): Natural and human causes and implications for water resources, ecosystems, economy, and society. Water Resour. Res., 49, 10401057, doi:10.1002/wrcr.20123.

Van Loon, A. F., 2015: Hydrological drought explained. Wiley Interdiscip. Rev.: Water, 2, 359-392, doi:10.1002/wat2.1085.

- M. H. J. Van Huijgevoort, and H. A. J. Van Lanen, 2012: Evaluation of drought propagation in an ensemble mean of large-scale hydrological models. Hydrol. Earth Syst. Sci., 16, 4057-4078, doi:10.5194/hess-16-4057-2012.

_- E. Tijdeman, N. Wanders, H. A. J. Van Lanen, A. J. Teuling, and R. Uijlenhoet, 2014: How climate seasonality modifies drought duration and deficit. J. Geophys. Res. Atmos., 119, 4640-4656, doi:10.1002/2013JB010791.

Velicogna, I., and J. Wahr, 2006: Measurements of time-variable gravity show mass loss in Antarctica. Science, 311, 1754-1756, doi:10.1126/science.1123785.

$\_$, and — 2013: Time-variable gravity observations of ice sheet mass balance: Precision and limitation of the GRACE satellite data. Geophys. Res. Lett., 40, 3055-3063, doi:10.1002/grl.50527.

_ surface water storage in discontinuous permafrost areas of the Lena River basin, Eurasia, detected from GRACE. Geophys. Res. Lett., 39, L09403, doi:10.1029/2012GL051623.

Vicente-Serrano, S. M., S. Begueía, and J. I. López-Moreno, 2010a: A multiscalar drought index sensitive to global warming: The standardized precipitation evapotranspiration index. J. Climate, 23, 1696-1718, doi:10.1175/2009JCLI2909.1.

,,,--- M. Angulo, and A. E. I. Kenawy, 2010b: A new global $0.5^{\circ}$ gridded dataset (1901-2006) of a multiscalar drought index: Comparison with current drought index datasets based on the Palmer drought severity index. J. Hydrometeor., 11, 1033-1043, doi:10.1175/2010JHM1224.1.

_ , and Coauthors, 2014: Evidence of increasing drought severity caused by temperature rise in southern Europe. Environ. Res. Lett., 9, 044001, doi:10.1088/1748-9326/9/4/044001.

Wahr, J., M. Molenaar, and F. Bryan, 1998: Time variability of the Earth's gravity field: Hydrological and oceanic effects and their possible detection using GRACE. J. Geophys. Res., 103, 30 205-30 229, doi:10.1029/98JB02844.

mass estimates. Geophys. Res. Lett., 33, L06401, doi:10.1029/ 2005 GL025305.

Wang, H., J. C. Rogers, and D. K. Munroe, 2015: Commonly used drought indices as indicators of soil moisture in 
China. J. Hydrometeor., 16, 1397-1408, doi:10.1175/ JHM-D-14-0076.1.

Wang, X., H. Xie, H. Guan, and X. Zhou, 2007: Different responses of MODIS-derived NDVI to root-zone soil moisture in semiarid and humid regions. J. Hydrol., 340, 12-34, doi:10.1016/ j.jhydrol.2007.03.022.

Watkins, M. M., D. N. Wiese, D.-N. Yuan, C. Boening, and F. W. Landerer, 2015: Improved methods for observing Earth's time variable mass distribution with GRACE using spherical cap mascons. J. Geophys. Res. Solid Earth, 120, 2648-2671, doi:10.1002/2014JB011547.

Webster, P. J., V. E. Toma, and H.-M. Kim, 2011: Were the 2010 Pakistan floods predictable? Geophys. Res. Lett., 38, L04806, doi:10.1029/2010GL046346.

Wiese, D. N., F. W. Landerer, and M. M. Watkins, 2016: Quantifying and reducing leakage errors in the JPL RL05M GRACE mascon solution. Water Resour. Res., 52, 7490-7502, doi:10.1002/2016WR019344.

Wu, D., X. Zhao, S. Liang, T. Zhou, K. Huang, B. Tang, and W. Zhao, 2015: Time-lag effects of global vegetation responses to climate change. Global Change Biol., 21, 3520-3531, doi:10.1111/gcb.12945.
Yang, Y., D. Long, H. Guan, B. R. Scanlon, C. T. Simmons, L. Jiang, and X. Xu, 2014: GRACE satellite observed hydrological controls on interannual and seasonal variability in surface greenness over mainland Australia. J. Geophys. Res., 119, 2245-2260, doi:10.1002/2014JG002670.

Yirdaw, S., K. Snelgrove, and C. Agboma, 2008: GRACE satellite observations of terrestrial moisture changes for drought characterization in the Canadian Prairie. J. Hydrol., 356, 8492, doi:10.1016/j.jhydrol.2008.04.004.

Yoshida, Y., and Coauthors, 2015: The 2010 Russian drought impact on satellite measurements of solar-induced chlorophyll fluorescence: Insights from modeling and comparisons with parameters derived from satellite reflectances. Remote Sens. Environ., 166, 163-177, doi:10.1016/j.rse.2015.06.008.

Zeng, N., J.-H. Yoon, J. A. Marengo, A. Subramaniam, C. A. Nobre, A. Mariotti, and J. D. Neelin, 2008: Causes and impacts of the 2005 Amazon drought. Environ. Res. Lett., 3, 014002, doi:10.1088/1748-9326/3/1/014002.

Zhao, M., G. A, I. Velicogna, and J. Kimball, 2017: Satellite observations of regional drought severity in the continental United States using GRACE-based terrestrial water storage changes. J. Climate, doi:10.1175/JCLI-D-16-0458.1, in press. 